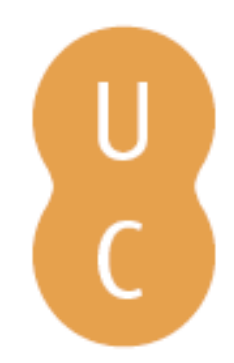

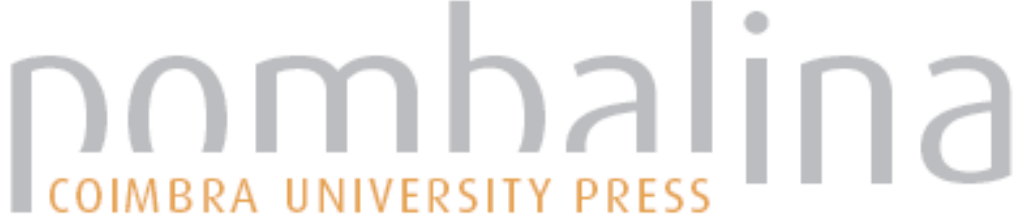

\section{Racionalização da nomenclatura química em Portugal}

\author{
Autor(es): $\quad$ Costa, A. M. Amorim da
}

Publicado por: Imprensa da Universidade de Coimbra

URL

persistente: $\quad$ URI:http://hdl.handle.net/10316.2/32400

DOI: $\quad$ DOI:http://dx.doi.org/10.14195/978-989-26-0469-5_15

Accessed : $\quad$ 26-Apr-2023 14:28:13

A navegação consulta e descarregamento dos títulos inseridos nas Bibliotecas Digitais UC Digitalis, UC Pombalina e UC Impactum, pressupõem a aceitação plena e sem reservas dos Termos e Condições de Uso destas Bibliotecas Digitais, disponíveis em https://digitalis.uc.pt/pt-pt/termos.

Conforme exposto nos referidos Termos e Condições de Uso, o descarregamento de títulos de acesso restrito requer uma licença válida de autorização devendo o utilizador aceder ao(s) documento(s) a partir de um endereço de IP da instituição detentora da supramencionada licença.

Ao utilizador é apenas permitido o descarregamento para uso pessoal, pelo que o emprego do(s) título(s) descarregado(s) para outro fim, designadamente comercial, carece de autorização do respetivo autor ou editor da obra.

Na medida em que todas as obras da UC Digitalis se encontram protegidas pelo Código do Direito de Autor e Direitos Conexos e demais legislação aplicável, toda a cópia, parcial ou total, deste documento, nos casos em que é legalmente admitida, deverá conter ou fazer-se acompanhar por este aviso. 
Ana Leunar Pereira João Rui Pita

[ Coordenaçä̃ ]
Rotas da Natureza

Cientistas

Viagens

Expedifgũes

Instituip̧ües

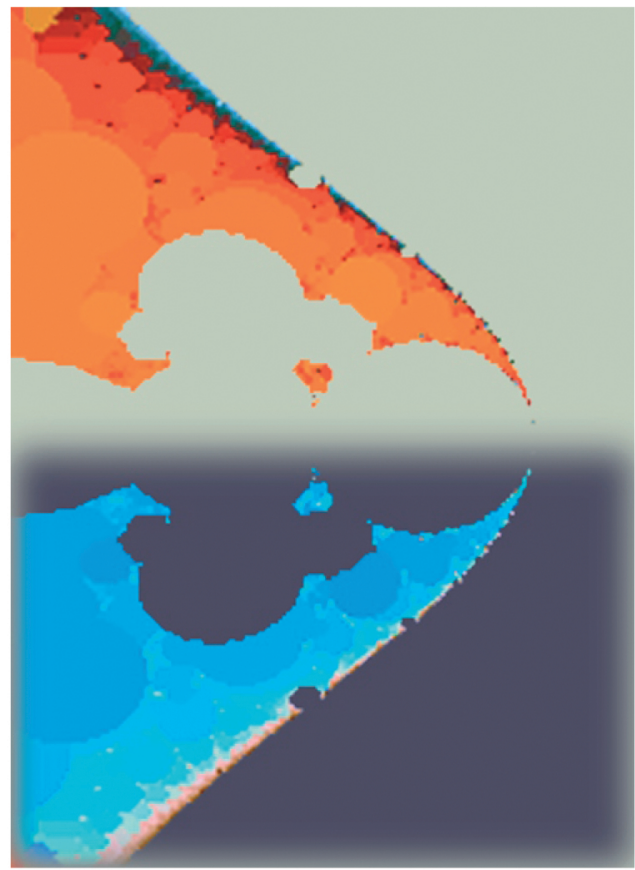




\section{Coordenaçáo Científica da Colecção Ciências e Culturas}

João Rui Pita e Ana Leonor Pereira

Os originais enviados são sujeitos a apreciação científica por referees

\section{Coordenação Editorial}

Maria João Padez Ferreira de Castro

\section{Edição}

Imprensa da Universidade de Coimbra

Email:impresauc@ci.uc.pt

URL: http://www.imp.uc.pt • Normas de publicação de colecçôes

\section{Design}

António Barros

Pré-Impressáo

António Resende

Imprensa da Universidade de Coimbra

\section{Capa}

António Barros, com imagem de E. M. de Melo e Castro, 2003 [Fractal original gerado no Fractint com tratamento no Photoshop 7.0]; Cortesia: António Barros

Impressão e Acabamento

SerSilito • Maia

\section{ISBN}

978-989-8074-12-6

\section{Depósito Legal}

Obra publicada com a colaboraçáo de:
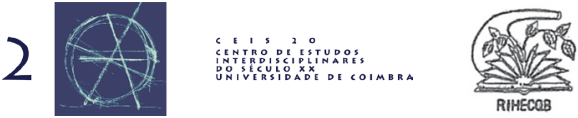

Obra publicada com o apoio de:

FCT Fundação para a Ciência e a Tecnologia

MINISTÉRIO DA CIÊNCIA, TECNOLOGIA E ENSINO SUPERTOR Portug

Programa Operacional Ciência, Tecnologia, Inovação do Quadro Comunitário de Apoio III
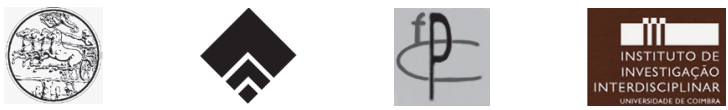

\section{Baxter}

(c) 2006, Imprensa da Universidade de Coimbra 
João Rui Pita

Ana Leonar Pereira

(Courdenação)

Rotas da Natureza

Cientistas

Viagens

Expediçũes

Instituiç̃̃es

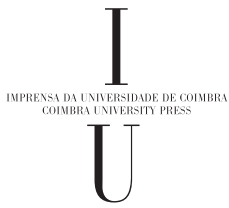

- colmbra 2006 
(Página deixada propositadamente em branco) 


\section{A. M. Amorim da Costa}

Dept. de Química - Fac. de Ciências e Tecnologia - Universidade de Coimbra, Portugal

\section{Racionalização da nomenclatura Química EM Portugal}

\section{No reino da química espagírica}

A partir da segunda metade do século XVI até ao terceiro quartel do séc. XVIII, a Química foi totalmente enquadrada na arte médica, constituindo o que ficou conhecido por medicina espagírica, iatroquímica ou farmacoquímica. No seu Tratado de Química, Christophe Glaser (1628-1672), definia-a como a arte científica cujo objectivo era dissolver os corpos para deles extrair as várias substâncias de que são compostos, e juntá-las de novo de modo a formar compostos mais puros e superiores ${ }^{1}$. Toda ela se funda em Princípios activos e passivos em que se baseiam todas as suas manipulações e artefactos. Nela se considera pelo mercúrio, o evaporável; pelo enxofre, o inflamável; e pelo sal, o solúvel. Por isso ficou conhecida como "a química dos princípios» 2 .

O carácter prático desta química aplicada à medicina e à farmácia, traduziu-se, nos dois séculos em que vigorou, num exame de caracterização do arquê de todas as coisas. Para J. B. Van-Helmont e seus discípulos, ele seria o "Alkaest», um princípio que tudo dissolvia; para J. Mayow, R. Boyle e outros, ele seria o nitro, um "princípio engendrado pelo próprio sol», no dizer de N. Lefebvre, origem e causa do perpétuo antagonismo ácido-alcali. A sua consideração e apresentação pormenorizada tornouse o objecto de atractivos manuais, de venda fácil, entre os quais se podem referir o Tyrocinium Chymicum (1610) de J. Béguin, o Traité de la Chimie (1663) de Christophe Glaser, o Traité de Chimie (1664) de Nicasius Lefebvre, a Physica Subterranea (1669) de J. J. Becher, o Tractatus Quinque Medico-Phisici (1674) de J. Mayow, e o Cours de Chimie (1675) de N. Lémery.

O sucesso destes manuais deve-se ao sucesso do ensino e da prática a que se reportavam. De facto, desde os princípios dos anos seiscentos, tratava-se de matéria que era ensinada em todas as Faculdades de Medicina e que nenhum dos praticantes de farmácia dispensava.

\footnotetext{
${ }^{1}$ Christophe Glaser, Traité de la Chimie, Paris, L'autheur ed., 1663, p. 3.

${ }^{2}$ M. Daumas, La Chimie des Principes in Histoire Générale des Sciences (Paris, Ed. René Taton, Presses Universitaires de France), Tom. II, 1972, cp. VI, pp. 354-367.
} 
Não é difícil ler esses manuais. Do ponto de vista explicativo, durante a segunda metade do século XVII e durante quase todo o século XVIII, a atenção dos seus autores virou-se cada vez mais para os problemas relacionados com a natureza da combustão e a natureza das forças actuantes nos compostos químicos: com G. E. Stahl (1660-1734), a explicação da combustão dos corpos acabou por se constituir no centro de toda a doutrina química, até finais do século XVIII, sendo a partir dela que se deu a revolução química de A. L. Lavoisier (1743-1794); por sua vez, com E. F. Geoffroy (1672-1731), a grande explicação das forças actuantes nos compostos químicos foi buscada nas chamadas afinidades químicas.

Do ponto de vista da prática química, nesses manuais é notório um crescente interesse pela descoberta e caracterização de novos elementos e compostos, utilizando métodos quantitativos cada vez mais rigorosos tornados na base essencial e indispensável de toda a investigação a que se procedia e que culminou com um determinante avanço no domínio da química dos gases, nomeadamente na sua diferenciação ${ }^{3}$.

Do ponto de vista da terminologia que usam é notória a quase total ausência de qualquer sistematização na designação dos elementos e compostos químicos ${ }^{4}$, como é notório o recurso a grande número de vocábulos tirados do elenco das práticas alquímicas que ainda reinavam por toda a parte, embora já sem o esplendor que haviam conhecido nos séculos passados. A apologia de um certo secretismo continua expressa em muitos desses manuais, registando-se, todavia, em alguns deles, já uma rejeição frontal de tal prática.

\section{Da Polyanthea Medicinal de Curvo de Semmedo à Historologia Médica de Rodrigues de Avreu}

Esta é a nomenclatura química que encontramos em Portugal ao iniciar-se o século XVIII e que se prolonga até à introdução da química de Lavoisier, quase nos finais da década de oitenta desse século. Primeiro, nas Farmacopeias que no país foram editadas, em vernáculo, "para que em todos os lugares e Villas deste Reyno possa ser percebido" que "não pode haver mayor ignorância que escrever o que eu quero que todos os Portugueses saybaô, em lingua que nem todos os Portugueses entendem ${ }^{5}$; depois, em alguns Tratados e Manuais de matéria química que ao longo do século, no país, foram publicados antes da Reforma da Universidade, em 1772.

\footnotetext{
${ }^{3}$ H. M. Leicester, The Historical Background of Chemistry (New York, Dover Publ. Inc., 1956), p. 119 .

${ }^{4}$ Como exemplo desta falta de sistematização, permitimo-nos referi aqui que um manuscrito do século XVII de António Neri apresenta para o metal mercúrio 20 símbolos e 35 nomes difeerentes; e, num outro livro da mesma época, o chumbo era designado por 14 símbolos e 16 nomes. Vid. A. M. Nunes dos Santos in Nota de Apresentação da Edição Fac-similada do original de Méthode de Nomenclature Chimique (1787) de Morveau, Lavoisier, Berthollet e Fourcroy ( Lisboa, Petrogal, AS, 1991).

${ }^{5}$ João Curvo Semmedo, Polyanthea Medicinal, 3a edição, (Lisboa, Off. António Pedrozo Galram, 1716) Prólogo ao Leytor.
} 
Como representativos da situação de facto, tomaremos a Polyanthea Medicinal de Curvo de Semmedo e a Historologia Médica de Rodrigues de Avreu.

2.1. Nas primeiras décadas do século, é de facto, nas Farmacopeias-dispensatórios que se reflecte a adesão dos cientistas portugueses às mais modernas teorias e práticas químicas cultivadas à época, além fronteiras.. No decurso do século, a sua publicação atingiu um regime editorial que nunca conseguira antes, com a particularidade de serem redigidas em português. Por ordem cronológica das primeiras edições, o elenco deste tipo de literatura científica destinada à aprendizagem da arte de boticário, bem como à execução prática dos medicamentos e estudo, colheita e conservação das matérias primas, compreende a Polyanthea Medicinal de João Curvo Semmedo, com uma primeira edição ao fechar do século XVII, em 1697, reeditada, em vida do seu autor, em 1704 e em 1716. Seguiram-se-lhe a Pharmacopea Lusitana de D. Caetano de Santo António, editada em 1704 e reeditada em 1711, 1725 e 1754'; a Pharmacopea Ulyssiponense de Joam Vigier, editada em 17167; a Pharmacopea Tubalense de Manuel Rodrigues Coelho, editada em 17358; o Thesouro Apollineo Galenico, Chimico e Chirurgico de Joam Vigier, editado em 1745 que não se intitulando farmacopeia o é de facto, pois se trata, como se lê no título extenso, de um "compêndio de remédios para ricos e pobres», contendo a «individuação dos remédios simplices, compostos e químicos9; a Pharmacopea Portuense de António Rodrigues Portugal, editada em 176610; a Pharmacopea Mediana do inglês Ricardo Mead, editada em 176811; a Pharmacopea Dogmática de João Jesus Maria editada em 1772; e, já depois da Reforma Pombalina da Universidade de Coimbra, a Farmacopeia Lisbonense, publicada em 1785 e reeditada em 1802, a primeira farmacopeia com rótulo de oficial, organizada por Manuel Henriques Paiva ${ }^{12}$. Todas elas são repositório da nomenclatura química anterior à revolução química de Lavoisier, incluindo a Farmacopea Lisbonense, que, elaborada e publicada durante os anos em que esta revolução estava em curso, tem por autor um médico que só tardiamente viria a aceitar as doutrinas que dela saíram, como adiante referiremos.

Não há diferenças significativas entre as diferentes farmacopeias enumeradas no que respeita às características da nomenclatura química que usam. Aquilo que as diferencia

${ }^{6}$ D. Caetano de Santo António, Pharmacopea Lusitana, methodo pratico de preparar os medicamentos na forma galenica, com todas as receitas mais usuais (Coimbra, Off. João Antunes, 1704); Pharmacopea Lusitana Reformada (Lisboa, Real Mosteyro de S. Vicente de Fora, 1711).

${ }^{7}$ Joam Vigier, Pharmacopea Ulyssiponense, Galenica e Chimica que contem os Principios e Termos Gerais de huma e outra Pharmácia (Lisboa, Pascoal da Sylva, 1716).

${ }^{8}$ Manoel Rodrigues Coelho, Pharmacopea Tubalense Chemico-Galenica (Lisboa Occidental, Off. Antonio de Sousa Sylva, 1735).

9 Joam Vigier, Thesouro Apollineo Galénico, Chimico, Chirurgico (Lisboa, Off. Miguel Rodrigues, 1745).

${ }^{10}$ António Rodrigues Portugal, Pharmacopea Portuense (Porto, Off. de Francisco Mendes Lima, 1766).

${ }^{11}$ Ricardo Mead, Pharmacopea Mediana, (Porto, Off. de Francisco Mendes Lima, 1768).

${ }^{12}$ Manoel Joaquim Henriques de Paiva, Farmacopeia Lisbonense (Lisboa, Off. de Filipe da Silva e Azevedo, 1785). 
é, na generalidade, o número e tipo de medicamentos que apresentam e os métodos práticos que referenciam para os preparar $^{13}$.

Por isso, uma análise do teor do dicionário químico-farmacêutico da Polyanthea Medicinal de Curvo de Semmedo em que se indicam os significados dos mais comuns nomes com que em diversos idiotismos se pedem os simples medicinais e se referem as operações da Arte química a ter em conta na sua preparação e utilização, dá-nos ideia bastante das características genéricas dessa nomenclatura.

Seguindo e citando abundantemente os mais conhecidos Tratados de Química da época em circulação além fronteiras, nela, a química é apresentada como a arte de abrir ou resolver todos os corpos compostos, purificando-os, para que os remédios que deles se fizerem tenham a maior virtude possível e obrem com a maior eficácia, numa acção toda orientada para o a sua manufactura ${ }^{14}$. Cumprindo este objectivo, à química se confiava a missão de aperfeiçoar ou transmutar os metais menos nobres usados pelos galénicos como remédios e que na natureza se encontram cheios de fezes, em metais mais nobres ${ }^{15}$ e a missão de buscar a razão da acção do vinagre como remédio utilíssimo para os que têm modorras, do calor como causa parcial das febres, da causa da acção dos quartanários e da acção dos espíritos fixos e voláteis, do apetite de quem vive no campo, da acção da saliva como primeiro mênstruo fermentativo existente na Natureza, da acção curativa do aço e dos coraes para as Camaras, da preparação do aço sudorífero, da acção do azougue e dos pós de joannes e do mercúrio doce, da fervura da cal virgem em água, da virtude do solimão e do ópio, e também das cousas gordas no estômago.

Defendendo os progressos verificados nos conhecimentos e práticas da química que progressivamente foram abandonando os medicamentos galénicos, nela se faz a apologia da doutrina dos três Princípios de Paracelso o sal, o enxofre e o azougue, sobre os quais se age recorrendo aos diversos graus de Fogo, formado por átomos ácido-nitro-aéreos que andam espalhados pelo $\mathrm{ar}^{16}$.

O autor reconhece a heterogeneidade do vocabulário usado pelos diversos químicos seus contemporâneos para designarem os melhores e mais eficazes remédios que propõem; e defende a novidade que muitos desses nomes representa em relação aos nomes usados pelos Boticários Galenistas, citando, a título de exemplo, Riverius que preferiu designar por calomelanos o mercúrio doce sublimado, pondo de lado a terminologia de Béguim que o designava Dragão Amansado; ou então, Theophrasto que ao Sal de Caparrosa passou a designar por Gilla; ou Poterius que ao Salitre chamava Sal Ermafrodito e Água seca; ou ainda, Lémery e Van-Helmont que usaram a designação genérica de Archeu para se referirem ao Espírito Vital ${ }^{17}$. Ao reconhecer a heterogeneidade do vocabulário usado pelos químicos seus contemporâneos e para obviar às múltiplas e acrescidas dificuldades inerentes à heterogeneidade duma tal terminologia,

${ }_{13}$ Rafael Folch y Andeu, As Farmacopeias portuguesas in Notícias Farmacêuticas, Coimbra, 10 (3-4), 1943/44, pp. 204-206.

${ }^{14}$ João Curvo Semmedo, Polyanthea Medicinal, loc. cit., Tratado III, cp. I, $₫ 1$, p. 693.

${ }^{15}$ Idem, Tratado III, cp. I, \$\$3-6, p. 693-694.

${ }^{16}$ Idem, Tratado III, cp. I, \$\$ 10-22, p. 695-697.

${ }^{17}$ Idem, Tratado III, cp. III, pp. 733-736. 
o autor não se furta ao trabalho de indicar o significado de muitos dos termos que usa e os nomes das diversas operações e utensílios químicos, indicando expressamente para que devem ser usados os diversos remédios cujas virtudes enumera ${ }^{18}$.

Ao fazê-lo, o autor justifica e defende as razôes dessa heterogeneidade que tem por justíssimas. Citamos: «usam os chymicos destes e de outros nomes semelhantes ou porque são os mais próprios dos seus significados, ou porque não querem que os segredos que lhes custaram incansável estudo, os saibam, às mãos lavadas, os inimigos da chymica, que a abominam em publico e a usam em secreto»; e fazem-no "para se estimarem porque conforme a Platão para que as Artes cresçam e se respeitem devem ocultar-se os segredos delas, ou explicar-se por enigma. E assim o entendeu também Thomas Muffetus o qual diz que nenhuma lei proibe que as cousas grandes se ocultem, ou expliquem debaixo de algum rebuço, para que as não saibam os que as não merecem; imitando nisso os exemplos da natureza, que não cria o ouro à flor da terra, gera o homem na profunda escuridade e clausura do ventre, cria as pérolas e aljofres no profundo dos mares, e ainda lá as encerra e esconde em humas conchas; cobre e esconde o miolo e substância da castanha, não só com huma casca dura, mas o defende com as agudas setas e defensivas armas dos seus espinhos» ${ }^{19}$.

2.2. Passando das Farmacopeias para outros Tratados e Manuais que no período pré-revolução científica de Lavoisier, em Portugal do século XVIII, versaram matéria química, merecem referência a Historologia Médica de José Rodrigues de Avreu ${ }^{20}$, os Elementos de Chimica e Farmácia de Manoel Joaquim Henriques de Paiva ${ }^{21}$ e as Instituiçôes ou Elementos de Farmácia de José Francisco Leal ${ }^{22}$. Publicada entre 1733 e 1752, a obra de J. Rodrigues de Avreu compreende, no dizer do seu autor, "as instituições químicas do sistema do engenhoso e famigerado George Ernesto Stahl, doutrina do presente, nascida na Prússia, mas com tantos créditos já em toda a Europa» ${ }^{23}$ A obra de Manoel J. Henriques de Paiva «a primeira Obra de Chimica que - no dizer de seu autor - em nossa lingoagem sáhe à luz» ${ }^{24}$, é na sua maior parte uma tradução do Manual de Scopol,um dos Manuais adoptados no ensino da Química na Universidade Reformada pelo Marquês de Pombal antes da adopção do sistema de Lavoisier. Por sua vez, a obra de J. Francisco Leal, publicada já ao tempo em que estava consumada a revolução química de Lavoisier, é uma adaptação do Manual de Baumé. Estas três obras representam bem a química flogística ensinada, defendida e difundida no nosso país, focando as suas mais significativas orientaçôes. A terminologia química que usam

${ }^{18}$ Idem, Tratado III, cp. III, 734-735; Cp. IV, pp. 736-756.

${ }^{19}$ Idem, Trat. III, cp. III, \&10, p. 736.

${ }^{20}$ Joseph Rodrigues de Avreu, Historologia Médica: Tom. I (Lisboa Occidental, Off. da Musica, 1733); Tom. II, Pt. I (Lisboa Occidental, Off.de António de Sousa da Sylva, 1739); Tom. II, Pt. II (Lisboa, Off. Francisco da Sylva, 1745); Tom. II, Pt. III (Lisboa, Off. Francisco da Silva, 1752).

${ }^{21}$ Manoel Joaquim Henriques de Paiva, Elementos de Chimica e Farmácia (Lisboa, Real Academia das Sciencias, 1783).

${ }^{22}$ José Francisco Leal, Instituições ou Elementos de Farmácia (Lisboa, Off. de António Gomes, 1792).

23 Joseph Rodrigues de Avreu, op. cit., Tom. I, Prefácio.

${ }^{24}$ Manoel Joaquim Henriques de Paiva, op. cit., Dedicatória. 
é, a par e passo, a terminologia dos originais estrangeiros que importaram para uso no nosso país, a maior parte dos grandes químicos da época, nomeadamente, Venel (1723-1775), Bergman (1735-1784), Louis Lémery (1677-1743), Guyton de Morveau (1737-1816), Pierre-Joseph Macquer, Antoine Baumé (1728-1804), Fourcroy (1755-1809), Priestley (1733-1804). Na primeira metade do século XVIII, com escola feita, talvez só Boerhaave (1668-1738), Professor de Medicina, Botânica e Química em Leiden, se tenha mantido à margem da teoria flogista de Stahl, embora as suas ideias se conformem facilmente com o esquema geral da mesma. A grande batalha de Lavoisier por uma nova química foi travada precisamente contra a teoria do flogisto. E não foi uma batalha fácil. Mesmo alguns dos seus mais chegados colaboradores só acabariam por abandoná-la já muito depois de Lavoisier ter proclamado que havia vencido. Priestley, por exemplo, acabaria por morrer sem nunca dela ter abdicado.

Conceptualmente cativante, a teoria do flogisto não desenvolveu para si qualquer sistema de nomenclatura química peculiar. Generalizaram-se os termos relacionados com a possível natureza e identificação do flogisto, como se generalizou o uso das Tabelas de afinidades, muitas delas com terminologia específica, mas as características gerais da terminologia química que vinha do anterior manteve-se.

2.3. Evitando desnecessárias repetições, aqui referiremos, por isso, apenas a terminologia química da Historologia Médica de J. Rodrigues de Avreu ${ }^{25}$.

No que respeita à terminologia química que usa, importa folhear os livros dois e três do Tom. I onde J. Rodrigues de Avreu, a propósito do corpo humano, se refere à composição dos corpos; e os oito livros da primeira parte do Tom. II, onde são apresentados os remédios a usar para tentar restabelecer a saúde perdida, nos diferentes e variados tipos de enfermidade.

Conformando-se cegamente com as Instituições químicas de Stahl, o autor descreve o corpo humano como uma pulquérrima fábrica onde a Natureza ou Calido Innato é a Alma Racional ${ }^{26}$. Os elementos desse corpo, como de qualquer corpo em geral, são três: a Água, o Pinguedo (ou Óleo) e a Terra. A Terra é muito ténue e facilmente se resolve em Água, à qual se une. A Alma Racional é o Agente vital que actuando sobre esses Principios lhes dá vida, o agente responsável pela circulação das diversas partes do sangue, a lympha, o soro e demais humores, o Espírito elaborado no coração e convertido no cérebro em "succo nervoso».

Por sua vez, na primeira parte do Tom. II, na descrição dos remédios a aplicar para restituir aos enfermos a saúde perdida, deparamo-nos com a história e qualidade dos vomitórios preparados com vegetais (a água escorcineira, o extracto de Losna, o extracto de Therical, a essência de Eleboro, o cypo, a cebola Albarran, a graciola ou gratia Dei, a sempre noiva vermicular, etc.), lado a lado com os vomitórios de antimónio, mercúrio e vitríolo (o antimónio detonado, o mercúrio precipitado branco, o ouro da vida de Keglero, os cristais da lua, etc.); a história e qualidade dos laxantes

\footnotetext{
25 Joseph Rodrigues de Avreu, Historologia Médica: Tom. I (Lisboa Occidental, Off. da Musica, 1733); Tom. II, Pt. I (Lisboa Occidental, Off.de António de Sousa da Sylva, 1739); Tom. II, Pt. II (Lisboa, Off. Francisco da Sylva, 1745); Tom. II, Pt. III (Lisboa, Off. Francisco da Silva, 1752).

${ }^{26}$ Idem, Tom. I, Liv. II, Summario, pp. 200-202.
} 
(a norça branca, a canafistola, os hermodactylos, etc.); a história e qualidade dos alviducos diaforéticos e sudatórios (a angelica, a anthora, a bistorta, o unicórnio fóssil e o verdadeiro, o veado succinado ou sal de Alambre, etc.); a história e qualidade dos diuréticos (toda uma variedade de raízes e também as flores de Bellis e de Plínio, a virgem aurea, etc); e ainda a história e qualidade dos errhinos e esternutatórios e outros expectorantes, bem como dos engrossantes, dos excitantes e dos remédios específicos para alguns tipos particulares de doenças, os simpatéticos, os arqueais ou os mumiais, onde se contam, entre muitos outros, o benjoim, uma goma índica, os rós ou sponsa solis, o millefólio para as hemorróides e cólicas intestinais, etc... ${ }^{27}$

\section{A nomenclatura química da escola de Lavoisier}

3.1. Nas décadas de setenta e oitenta do século dezoito, Lavoisier reformolou toda a química relativa à combustão dos corpos, baseando-se na acção do oxigénio. Ao fazê-lo refutou arduamente toda a doutrina química baseada na acção do flogisto. A reformulação foi tão vasta que ele próprio a considerou uma verdadeira «revolução química».No processamento desta "revolução, Lavoisier estabeleceu definitivamente a composição do ar atmosférico e a composição da água, pondo em causa a teoria dos quatro elementos, Terra, Ar, Fogo e Água. Em lugar destes, foram tidos como substâncias elementares outras, em número muito maior. Lavoisier viria a elaborar uma Tabela de substâncias simples onde, em vez desses quatro elementos encontramos trinta e três, distribuídas por quatro classes ${ }^{28}$.

$\mathrm{Na}$ Suécia, Lineu levara a cabo uma sistematização da nomenclatura para a Botânica que fora muito bem aceite pela comunidade científica Pela mesma altura, em França, fazia-se sentir cada vez mais a influência do abade Étienne de Condillac (1715-1780) que no seu Traité des Systèmes (1749) e, sobretudo, no seu tratado La Lógique ou Premiers Dévelopments de l'Art de Penser, editado em 1781 onde afirmava a necessidade da importância duma linguagem simples e sistemática para o bom desenvolvimento e prática de qualquer ciência. As palavras perpetuam os erros e preconceitos e daí que a linguagem não seja apenas expressão do pensamento, mas também instrumento da sua produção.

Arrastado por esta filosofia de Condillac e desejoso de se ver liberto do emaranhado da terminologia que então reinava no domínio da química, Lavoisier sentiu claramente que não podia ser bem sucedido na implementação da nova ciência química se não conseguisse dotá-la de uma nova nomenclatura, substituindo a simbologia alquímica e o marasmo da terminologia espagírica por uma linguagem racional e sistemática em que houvesse uma relação biunívoca entre os nomes usados e as coisas a que se referiam. Com Guyton de Morveau, Claude L.Berthollet e François de Fourcroy preparou um conjunto de comunicaçóes sobre o assunto que foram apresentadas à Académie Royale

\footnotetext{
${ }^{27}$ Idem, Tom. II, Pt. I, Livs. III-IV.

${ }^{28}$ Antoine L. Lavoisier, Traité Élémentaire de Chimie (Paris, Chez Cuchet Lib.,1789), p. 140.
} 
des Sciences de Paris, na forma de Mémoires, em Abril e Maio de 1787, depois reunidas num só volume, com o título Méthode de Nomenclature Chimique ${ }^{29}$.

A nova nomenclatura química que propunha baseava-se, essencialmente em dois princípios: o papel fundamental atribuído ao oxigénio na formação de ácidos e sais e a constituição binária dos nomes subjacentes ao carácter dualístico da composição dos sais inorgânicos. Construída sobre uma linguagem clara e simples, rigorosa e precisa - «as denominações devem ser, tanto quanto possível, em conformidade com a natureza das coisas» - a nova nomenclatura sobreviveu, às novas teorias e às novas descobertas e foi-se adaptando bem a umas e a outras. Objecto de variadas revisões e reformas, ela é ainda hoje, a base das denominações usadas pela ciência química. Lavoisier e seus colaboradores não tiveram grandes dificuldades em impor a nova nomenclatura química que propunham, não obstante algumas resistências iniciais.

3.2. Em Portugal, foi na Universidade de Coimbra reformada pelo Marquês de Pombal que as doutrinas de Lavoisier encontraram os primeiros adeptos.

Dos primeiros graduados do novo Curso de Filosofia contratados para a docência do mesmo curso e que deixaram, por seus escritos, testemunho público sobre a química que defenderam e praticaram, destacam-se os nomes de Manoel Joaquim Henriques de Paiva (1752-1829), Thomé Rodrigues Sobral (1759-1829) e Vicente Coelho de Seabra (1764-1804).

Ainda estudante de Medicina na Universidade de Coimbra, Manoel Joaquim Henriques de Paiva iniciou funçôes de demonstrador de Química e de História Natural, de Maio de 1773 até 1777, data em que deixou a Universidade de Coimbra, e foi viver para Lisboa, onde exerceu como Médico da Corte e sempre manteve intensa actividade no domínio da química. Encarregado da regência da cadeira de Farmácia na Casa Pia de Lisboa; leccionou Química e História Natural no Laboratório de Francisco José Aguiar; e foi Redactor Principal do Jornal Encyclopédico. No âmbito da sua vasta actividade como químico, publicou os já mencionados Elementos de Química e Farmácia (1783), a Farmacopeia Lisbonense (1785), e, usando os elementos extraídos e adaptados por José Francisco Leal.da obra de Baumé, as Instituições ou Elementos de Farmácia (1792) e ainda várias Memórias de História Natural, de Química, Agricultura, Artes e Medicina, lidas na Academia Real das Sciencias de Lisboa (1790). Em todas estas suas obras, M. J. Henriques de Paiva não só não seguiu as novas teorias, como as atacou e criticou severamente, aqui e ali, como o provam algumas notas e recensóes críticas que fez no Jornal Encyclopédico. A linguagem química que usa é por inteiro a linguagem da química flogística que exemplificámos com o teor da Historologia Médica de J. Rodrigues de Avreu. Só tardiamente, M. J. Henriques de Paiva aderiu à química de Lavoisier, quando, já nos inícios do século XIX se deixou conquistar pela obra de Fourcroy que traduziu de francês para português, em repetidas ediçôes ${ }^{30}$.

${ }^{29}$ Méthode de Nomenclature Chimique, proposée par M. M. de Morveau, Lavoisier, Berthollet \& de Fourcro. On y a join un nouveau système de caractères chimiques, adaptés à cette nomenclature par $M$. M. Hassenfratz e Adet (Paris, Chez Cuchet, Lib., 1787).

${ }^{30}$ Sobre a vida académica de Manoel Joaquim Henriques de Paiva e a sua obra veja-se: O. Carneiro Guiffoni, Presença de Manoel Joaquim Henriques de Paiva na Medicina Luso-Brasileira do século XVIII (S. 
Em particular, os seus Elementos de Quimica e Farmácia foram objecto de forte crítica por parte de Francisco Raimundo Xavier da Costa (?-1794) que sobre eles escreveu um grosso volume, em que ao longo de dez capítulos e quase quatrocentas páginas escalpela não só os muitos erros que considera neles contidos, como a orientação seguida, as explicaçôes doutrinais apresentadas e a terminologia usada ${ }^{31}$.

Bem diferente da posição de Manoel Joaquim Henriques de Paiva é a posição de Thomé Rodrigues Sobral e Vicente Coelho da Silva Seabra Telles, também eles dos primeiros discipulos de Vandelli, formados pela nova Faculdade de Filosofia da Universidade de Coimbra que nela assumiram funçôes de docência química. Contratados para o exercício destas funções quando terminaram a sua graduação, nelas serviram até à morte, sucedendo na cátedra a Domingos Vandelli, quando este se jubilou, em 1791: o Doutor Thomé Rodrigues Sobral, que fora antes demonstrador de Historia Natural e substituto extraordinário de Física, como lente de Chymica e Metalurgia e Director do Laboratorio Chymico; o ainda bacharel Vicente Coelho da Silva Seabra, como demonstrador da mesma cadeira ${ }^{32}$.

O alinhamento de Thomé Rodrigues Sobral ao lado dessas novas teorias ressalta claro do Prefácio que escreveu para o Tratado das Affinidades Chimicas, artigo que no Diccionário de Chimica, fazendo parte da Encyclopédia por ordem de matérias, deu Mr. Morveau, que ele próprio traduziu e a Real Imprensa da Universidade publicou em 1793; e foi explícitamente testemunhado por Link com base nos contactos pessoais que com ele manteve ao longo de 1797-1799. Os longos escritos químicos que publicou no Jornal de Coimbra ao longo das duas primeiras décadas do século XIX apontam no mesmo sentido, e impuseram-no então como o mais distinto e autorizado químico português da época ${ }^{33}$.

A tradução da nomenclatura química por ele elaborada a que se refere Link só viria a ser apreciada pela Congregação da Faculdade de Filosofia a 29 de Julho de 1824, embora Rodrigues Sobral, se refira a ela, em 1816, como estando pronta para ser publicada brevemente. Quanto ao Manual de Química que tinha em preparação sabe-se que o seu texto foi apresentado na Congregação da Faculdade de Filosofia de 31 de Julho de 1794, tendo sido nomeado seu censor Manuel José Barjona, e que foi aprovado até ao parágrafo 243, na Congregação da mesma Faculdade havida a 22 de Abril de 1795. Não se conhecem, todavia, quaisquer exemplares que tenham sido impressos; o próprio Thomé Rodrigues Sobral diz que todas as suas casas de habitação que possuia nos arredores da cidade, na Quinta da Cheira, foram, por retaliação, queimadas pelos invasores franceses, incluindo a sua preciosa biblioteca, não escapando

Paulo, Brasil, 1954); Mário da Costa Roque, Manuel Joaquim Henriques de Paiva, estudante coimbrão in Arquivo de Bibliografia Portuguesa, vol. 115 (1969), pp. 59-60; A. M. Amorim da Costa, João Rui Pita e J. P. Sousa Dias, Manoel Joaquim Henriques de Paiva e a difusão das novas doutrinas e práticas de química e farmácia em Portugal, (Segóvia, Congresso Louis Proust, 1992).

${ }^{31}$ Francisco Raimundo Xavier da Costa, Apologia Critico-Chimica e Pharmaceutica ao Primeiro Tomo da Obra intitulada: Elementos de Chimica e Farmárcia que há pouco deu à luz Manoel Joaquim Henriques de Paiva, Medico (Lisboa, Off. Part. Francisco Luiz Ameno, 1786), Prólogo.

32 Carta Régia de 24 de Janeiro de 1791.

33 José Feliciano de Castilho, Jornal de Coimbra, 7 (1814), pp. 296-7. 
ao incêndio um só volume, incluindo os seus preciosos manuscritos e especialmente o seu compêndio de química ${ }^{34}$.

De Vicente Seabra se deve dizer que foi ele quem primeiro usou extensa e sistematicamente a nova nomenclatura de Lavoisier em português, pelo que é justo considerá-lo como o seu verdadeiro introdutor na lingua portuguesa, como o considerou Jacinto da Costa na Pharmacopea Naval e Castrense, em $1819^{35}$.

Nomeado Demonstrador de Química e graduado gratuitamente no grau de Doutor da Faculdade de Filosofia, Vicente de Seabra publicou, na Real Impressão da Universidade, em 1787, uma Dissertação sobre a Fermentação em Geral, e suas Espécies $^{36}$, o primeiro escrito em português em que se defende a decomposição da água «em gaz inflamável, e ar puro, ou oxigénio» de acordo com as teses sustentadas por Lavoisier. Nesse mesmo ano apresentou na Congregação da Faculdade de Filosofia de 21 de Dezembro, para aprovação, o texto de um Manual de química, «offerecido à Sociedade Litterária do Rio de Janeiro para uso do seu Curso de Chimica», com o título Elementos de Chimica $^{37}$, cujo primeiro volume seria publicado no ano seguinte, e o segundo, em 1790.

Ao abrir da segunda parte do primeiro volume, Seabra refere que para se poder estudar e entender com facilidade a História Natural, «foi preciso que o grande Linneo e outros fizessem huma nomenclatura scientifica, e propria desta Sciencia» e que com muita mais razão se tornou necessário fazer o mesmo na química, «Sciencia muito mais extensa, do que aquella, pois trata de examinar todas as combinaçóes possíveis dos corpos huns com os outros»; "se não houver nomes scientíficos, que indiquem por si mesmos os componentes dos corpos, o estudo da chimica será difficíllimo, e a vida do homem muito curta para decorar nomes insignificativos, que longe de ajudarem a nossa fraca memoria a enfraquecem cada vez mais»; " a estes incovenientes ao progresso remediram os célebres Morveau, Lavoisier, Berthollet, Fourcroy, Hassenfratz e Adet com sua nova nomenclatura chimica». Porque "a nenhum sensato deixará de agradar semelhante terminologia», a "adoptamos, não levados da novidade, como alguns julgarão, mas persuadidos da sua utilidade real, e a accommodamos do modo possível ao idiotismo da nossa Lingoagem, da Latina, e Francesa, de sorte que se evitasse qualquer confusão, que podesse haver na mesma adopção ${ }^{38}$.

Em 1790, Vicente de Seabra abre o Segundo volume do seu Manual com duas citações e uma Advertência. As citações são do Methode de Nomenclature Chimique de Lavoisier e colaboradores e do Traité des Systèmes de Condillac, ambas elas para

${ }^{34}$ Vid., por exemplo, observaçōes em roda-pé em Thomé Rodrigues Sobral, Oratio pro Solemni Studiorum annuaque de more instauratione in Jornal de Coimbra, VII (1814), Pt. II, pp. 83-84; Idem, Sobre os Trabalhos em grande que no Laboratório Chimico da Universidade poderão praticar-se in Jornal de Coimbra, vol. IX (1816), Pt. I, p. 305.

35 Jacinto da Costa, Pharmacopea Naval e Castrense, 2 vols. (Lisboa, Impressão Régia, 1819), p. VI.

${ }^{36}$ Vicente Coelho de Seabra, Dissertação sobre a Fermentação em Geral, e suas Espécies (Coimbra, Real Impressão da Universidade, 1787).

${ }^{37}$ Vicente Coelho de Seabra, Elementos de Chimica (Coimbra, Real Officina da Universidade: Volume I - 1788; vol. II - 1790).

${ }^{38}$ Idem, vol I. Part. II, pp. 55-56. 
deixar claro que é impossível isolar a Nomenclatura da Ciência e a Ciência da Nomenclatura. Na Advertência faz profissão de fé no uso da nomenclatura moderna pelas razões que referiu no primeiro volume, remetendo os leitores expressamente para o citado Methode de Nomenclature Chimique, o Traité Élémentaire de Chimie que Lavoisier piblicara no ano anterior, e para o Prefácio da Nova Enciclopédia Metódica em que Bergmann enaltece também a nova Nomenclatura e reprova a antiga, citando Morveau. E conclui esta Advertência dizendo: "com tudo, para evitar confusôes, não uzo de palavras, que lhe não ajunte os seus synonymos antigos; nesta classe (a Classe II dos compostos químicos, os Corpos combustíveis, de que trata o volume em apresentação) porém porevitar confusôes uso somente dos termos novos, quando estes já estão explicados na primeira Classe (a Classe I dos compostos químicos, os corpos incombustíveis, tratada no primeiro volume); e indo-se ao índice geral ver-se-á onde estão os seus synonimos» ${ }^{39}$.

O uso, enaltecimento, defesa e utilização que Vicente de Seabra fez da nova nomenclatura química de Lavoisier culminariam com uma sua publicação, em 1801, com o título Nomenclatura Chimica Portugueza, Franceza e Latina a que se junta o systema de Characteres Chimicos Adaptados a Esta Nomenclatura por Haffenfratz e Adet ${ }^{40}$. Trata-se, usando as palavras do autor, duma sinonimia portuguesa, por ordem alfabética, dos compostos químicos conhecidos, acrescida da sinonimia francesa, e latina e, também, da sinonimia antiga. $\mathrm{Na}$ introdução, refere tratar-se da linguagem química que "toda a Europa tem já adoptado, uma linguagem analítica, única admissível nas Sciencias, e única apropriada para sua mais fácil intelligencia, e adiantamento». Já por toda a Europa, as Nações iluminadas a tinham adoptado; os Portugueses não deveriam ser excepção, "convencidos, como as outras nações, da sua bondade». Embora, com alguma adversidade e, sobretudo, com alguma irregularidade na etimologia que muitos adoptavam, pois uns seguiam a etimologia e desinência francesas, e outros a etimologia e desinência latinas, e outros, ainda, insdistintamente, uma ou outra, pelo que continuava a verificar-se nos escritos portugueses uma certa irregularidade, que facilmente se tornava fonte de confusão e não servia a uniformidade e exactidão que se pretendia nesta matéria, tornando-se antes lesiva da sua elegância e beleza, podendo torná-la monstruosa, escura e inútil para o seu fim. Não obstante, tornou-se rapidamente adoptada pela maioria dos químicos portugueses. E para obviar às discordâncias reinantes, o próprio Vicente Seabra se deu ao trabalho de apresentar. E, quadro sinóptico de fácil comparação, «a Synonimia Portugueza, e a Synonimia Franceza, e os Diccionarios Portuguez- Francez, Portuguez-Latino e François-Portugais», seguindo geralmente a etimologia latina e a desinência portuguesa "não somente porque o nosso idioma tem mais analogia com ella, como porque a dicção latina he hoje geralmente seguida em todas as obras chimicas e phisicas» ${ }^{41}$.

${ }^{39}$ Idem, vol, II, pgs. iniciais, não numeradas.

${ }^{40}$ Vicente de Seabra, Nomenclatura Chimica Portugueza, Franceza e Latina a que se junta o systema de Characteres Chimicos Adaptados a Esta Nomenclatura por Haffenfratz e Adet (Lisboa, Typographia Chalcographica, Typoplástica e Litterária do Arco do Cego, 1801).

${ }^{41}$ Idem, Introdução, pp. I-II. 
O uso das doutrinas e da nomenclatura de Lavoisier valeu a Vicente de Seabra várias críticas. Assim, no mesmo número em que noticiava a tradução espanhola do Methode de Nomenclature Chimique, sem qualquer juizo de valor ${ }^{42}$, o Jornal Encyclopédico, de Junho de 1788, na secção dedicada a Bibliografia, fazia a recensão da Dissertação sobre a Fermentação em geral, e suas Espécies, em termos pouco elogiosos. Referido o conteúdo da Dissertação em apreço, refere o autor da recensão: «em toda esta Dissertação não encontramos nada de novo, e ousamos afirmar que he quasi huma mera tradução, ou resumo do que sobre o assumpto diz Mr Fourcroy». Mesmo assim, o autor da recensão recomenda a leitura da Obra, pelas coisas interessantes que contém, e sobretudo pelas experiências, que trás acerca do Ether, feitas pelo author com muito cuidado e tino; as quaes fazem esperar que poderá algum dia dar à luz composições mais perfeitas e vir a ser com o tempo, assídua applicação e repetidas experiências, hum excellente químico». Mas critica duramente a terminologia que a Obra utiliza: «assim ele se esmerasse mais na adopção dos termos, e não introduzisse em tão pequena obra tantos vocábulos bárbaros, como por exemplo, acidez, acidificante, averdongada, alongada, cretosos, estrias, filamentos, glúten, imiscivel, lactênscia, lactescente, mucosidade, putrefacção, pútrida, retrogredir, robur, ficidez, tartaroso e outros muitos» ${ }^{42}$.

As críticas havidas não foram suficientes para obstar a que a nova terminologia química de Lavoisier se afirmasse e vingasse muito rapidamente na prática, ensino e estudo da química em Portugal, embora se tenham continuado a registar divergências várias sobre alguns dos termos propostos, ao longo das primeiras décadas do século XIX.

Em 1816, Thomé Rodrigues Sobral num trabalho "Sobre os Trabalhos em grande que no Laboratório Chimico da Universidade poderão praticar-se» ${ }^{43}$ ao apresentar o Catálogo dum grande número de produtos químicos, nomeados de acordo com a nomenclatura química de Lavoisier e ordenados por ordem alfabética que poderiam servir para a sua necessária programação, em nota de rodapé, a propósito de alguns dos produtos desse Catálogo, deixa-nos advinhar as querelas que continuavam a propósito de certos nomes.

Assim, ao referir-se aos "acetato d'alumina, ou aluminoso», ao acetato d'ammonia, ou acetato ammonial» e ao "acetato de baryta, ou barityco» faz notar que "este modo de exprimir por substantivo ou adjactivo qualquer sal he arbitrário; e he ordinariamente só a eufonia que regula a escolha. Estes três exemplos bastão por todos». E, um pouco mais adiante, ao referir a «ammonia caustica» faz notar: «hoje preferiremos a denominação ammonia e ammoniaes às de ammoniaca e ammoniacaes que se davam ao alcale volátil e suas combinaçôes ${ }^{44}$.

Todavia, o confessado propósito de Sobral e a necessidade que teve de elaborar nessa altura, a sua própria Memória sobre a nomenclatura química a usar, depois da racionalização que dela fizera Lavoisier, essa Memória a que nos referimos já, mostra-nos claramente que havia um esforço enorme entre os mais influentes químicos portugueses de então em impor, aperfeiçoar e utilizar a nova nomenclatura, deixando de vez

\footnotetext{
42 Jornal Encyclopédico, Lisboa, Junho 1788, pp. 244-245.

43 Thomé Rodrigues Sobral, Sobre os Trabalhos em grande que no Laboratório Chimico da Universidade poderão praticar-se in Jornal de Coimbra, vol. IX (1816), Pt. I, pp. 293-312.

${ }^{44}$ Idem, p. 299.
} 
aquela que haviam usado iatroquímicos e flogistas que na sua falta de sistematização tornava dificílimo o estudo da extensa matéria da ciência química pelo filósofo nela interessado, com «um tempo de vida por demais curto para decorar tantos e tantos nomes insignificativos» 


\section{Colecçãa \\ 2 Ciências e Culturas Caimbra 2006}

